\title{
The treatment of recurrent tracheo-oesophageal fistula with biosynthetic mesh
}

To the Editor: One of the most serious and frustrating complications after successful primary repair of a tracheoesophageal fistula is a recurrent fistula, ${ }^{1,2}$ the incidence of which is reported as $5-15 \%$. Secondary recurrences following fistula re-closure are also not uncommon. ${ }^{3}$ Traditional therapy for a recurrent tracheo-oesophageal fistula (RTF) involves a repeat thoracotomy, with its associated risks and significant morbidity. An endoscopic procedure provides an attractive alternative.

Use of a bronchoscopic technique was first reported in 1975 by Gdanietz and Krause, ${ }^{4}$ who used histo-acryl adhesive to close an RTF. Since then, a variety of other endoscopic techniques have been reported. The strategies employed in these techniques include plugging the fistula with fibrin glue or tissue adhesives, ${ }^{3}$ plugging it after de-epithelisation of the fistula, ${ }^{5,6}$ or obliteration of the fistula using cauterisation or laser therapy. ${ }^{7}$ More than one treatment session was needed in most of the cases reported in which these techniques were used.

Recently Keckler et al. ${ }^{8}$ reported successful obliteration of an RTF with two successive applications of Surgisis biological mesh (Cooke Inc., Bloomington, Ind.). Encouraged by their results, we used Permacol (TissueScience, Hampshire, UK), a porcine dermal biological mesh, on a 6-month-old baby with an RTF. Only a single application of Permacol was necessary.

In this patient, rigid bronchoscopy revealed a recurrent fistula a few millimetres proximal to the carina. To create a raw surface, de-epithelisation of the fistula tract was performed with an endoscopic brush. Using an endoscopic grasper, a $3 \mathrm{~mm} \times$ $3 \mathrm{~mm}$ piece of Permacol was introduced and pushed into the fistula until it was seen through a gastroscope to be close to the opening in the oesophagus. Four more similar pieces of Permacol were introduced. DuraSeal (Confluent Surgical Inc., Waltham, Mass.) was then injected into the fistula tract with an extended tip applicator. The DuraSeal was used to seal off the Permacol and keep it in position.

The patient was extubated and kept on nasogastric feeds for 48 hours, after which oral feeds were started. Postoperative recovery was uneventful. A postoperative oesophagram on day 4 was normal. The patient continued to recover and remained asymptomatic 24 months after this procedure.

Permacol provides a long-lasting and stable collagen lattice that allows the incorporation of fibroblasts and capillaries to form a growing scar. Experimental evidence suggests that the biosynthetic scaffold degrades over time, but that the tissue remodelling that replaces it is stronger than the native tissue. The use of biosynthetic mesh has gained wide acceptance. It has been used with encouraging results in the repair of diaphragmatic hernias, abdominal and thoracic wall defects and para-oesophageal hernias. ${ }^{9-11}$

The bronchoscopic placement of biosynthetic mesh is an added modality in the treatment of the difficult problem of RTF, and holds great promise. This bronchoscopic procedure is easy to perform and is repeatable if necessary. It is a much less invasive and less risky procedure than the alternative, repeat thoracotomy, and should be considered as a good treatment option for patients with an RTF.

\section{L van Niekerk \\ Department of Paediatric Surgery \\ University of Pretoria}

\section{W L Roos}

Montana Hospital

Pretoria

\section{REFERENCES}

1. Ein SH, Stringer DA, Stephens CA, et al. Recurrent tracheoesophageal fistulas: seventeen-year review. J Pediatr Surg 1983;18:436-441.

2. Willets JE, Dudley NE. Endoscopic treatment of recurrent tracheoesophageal fistula. Long-term results. Pediatr Surg Int 1998;13:256-258.

3. Wiseman NE. Endoscopic closure of recurrent tracheoesophageal fistula using Tisseel. J Pediatr Surg 1995;30:1236-1237.

4. Gdanietz K, Krause I. Plastic adhesives for closing oesophago-trachea fistulae in children. Z Kinderchir 1975;17:137-138.

5. San Román CG, Barrios JE, Lluna J, et al. Long-term assessment of the treatment of recurrent tracheoesophageal fistula with fibrin glue associated with diathermy. Pediatr Surg 2006;41:1870-1873.

6. McGahren ED, Rodgers BM. Bronchoscopic obliteration of recurrent tracheoesophageal fistula in an infant. Pediatric Endosurgery \& Innovative Techniques 2001;5:37-39.

7. Bhatnagar V, Lal R, Sriniwas M, et al. Endoscopic treatment of tracheoesophageal fistula using electrocautery and the Nd: YAG laser. J Pediatr Surg 1999;34:464-467.

8. Keckler SJ, St Peter SD, Calkins CM, et al. Occlusion of a recurrent tracheoesophageal fistula with Surgisis. J Laparoendosc Adv Surg Tech 2008;18:465-467.

9. Smith MD, Campbell RM. Use of biodegradable patch for reconstruction of large thoracic cage defects in growing children. J Pediatr Surg 2006;41:46-49.

10. Grethel EJ, Cortes RA, Wagner AJ, et al. Prosthetic patches for congenital diaphragmatic hernia repair: Surgisis vs. Gore-Tex. J Pediatr Surg 2006;41:29-33.

11. Oelschlager BK, Barreca M, Chang L, et al. The use of small intestine submucosa in the repair of paraesophageal hernias: Initial observations of a new technique. Am J Surg 2003;186:4-8.

\section{S Afr J Surg 2012;50(3):106. DOI:10.7196/SAJS.1054}

